\title{
CANCER
}

\section{Flat and depressed colorectal tumours in a southern Swedish population: a prospective chromoendoscopic and histopathological study}

\author{
S Tsuda, B Veress, E Tóth, F-T Fork
}

See end of article for authors' affiliations

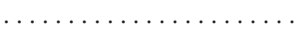

Correspondence to: Dr B Veress, Department of Pathology, University Hospital MAS, 20502 Malmö, Sweden: bela.veress@skane.se

Accepted for publication 15 January 2002

\begin{abstract}
Background: Flat and depressed colorectal tumours are common in Japan but are very rare or nonexistent in Western countries.

Aims: To study the occurrence of flat colorectal tumours in a southern Swedish population.

Methods: In this prospective study, 371 consecutive European patients were examined by high resolution video colonoscopy combined with chromoendoscopy. The nature of the lesions was determined by histopathological examination.

Results: A total of 973 tumours were found; $907(93.2 \%)$ were protruding and $66(6.8 \%)$ were flat or depressed. Of the flat/depressed tumours, five (7.7\%) were early adenocarcinomas infiltrating the submucosa. Eleven carcinomas (1.2\%) were found among protruding tumours. High grade dysplasia was observed in $18 \%(n=11)$ of flat/depressed adenomas in contrast with $7.3 \%(n=65)$ of protruding adenomas, and occurred in smaller flat/depressed tumours compared with protruding ones (mean diameter $8 \mathrm{~mm} v 23 \mathrm{~mm}$, respectively). Furthermore, high grade dysplasia was significantly more common in flat elevated tumours with central depression or in depressed adenomas $(35.7 \% ; 5 / 14)$ than in flat elevated adenomas (12.8\%; 6/47).

Conclusion: Flat and depressed tumours exist in a Western population. Future studies should address whether or not chromoendoscopy with video colonoscopy is necessary in the search for flat colorectal neoplasms.
\end{abstract}

C olorectal tumours can grow either as exophytic polypoid masses, depressed and ulcerated neoplasms, or remain largely at the level of the normal mucosa forming flat lesions. The exophytic adenomas are slowly growing and can transform to invasive carcinoma after a dwell time of 10-15 years, according to the generally accepted theory of the adenoma-carcinoma sequence. Approximately $70 \%$ of all colorectal carcinomas belong to this category. ${ }^{1-3}$ The remaining $30 \%$ are the so-called de novo cancers which have been described by both Western and Japanese authors. ${ }^{4-6}$ The idea of flat adenomas being precursor of these tumours is close at hands, although definitive proof is still lacking. Flat colorectal adenomas were first described by Muto et al in 1985. ${ }^{7}$ Since then, several hundred flat adenomas have been analysed in Japan..$^{8-12}$ Flat adenomas are regarded either as rare tumours in Western countries ${ }^{13}$ or are not considered as a separate disease entity. ${ }^{14}$ The reported high incidence of high grade dysplasia and early transformation to invasive carcinoma is thought to be the result of over interpretation by Japanese pathologists ${ }^{14}$ or differences in classification between Japanese and Western pathologists. ${ }^{15}$ Because of these differences in opinion, the phenomenon of flat colorectal adenomas has been the subject of several editorials. ${ }^{13-14}$ 16-17 $^{17}$ Based on a review of 178 flat tumours from a Japanese material by a Western trained pathologist from Karolinska Hospital, Stockholm, Sweden, the Japanese standpoints were supported. ${ }^{9}{ }^{18}$

We have found only seven Western reports describing larger series of flat adenomas. Six of these studies were prospective. The percentage of flat and depressed tumours both in the population and among neoplasms described in these reports is summarised in table 1 . We initiated a prospective colonoscopic and histopathological study to establish whether flat and depressed adenomas exists in a southern Swedish population at high risk of colorectal carcinoma. Our paper describes the results of this two year study showing that flat adenomas, often with high grade dysplasia, are part of the spectrum of colorectal neoplasias in the Swedish population.

\section{MATERIAL AND METHODS}

Between 1 November 1993 and 31 October 1995, 1328 colonoscopic investigations were performed in 1189 patients (fig 1)

Table 1 Summary of Western reports of larger series of flat colorectal tumours

\begin{tabular}{|c|c|c|c|c|}
\hline Source & Type of study & $\begin{array}{l}\text { No of patients with } \\
\text { flat lesions/all pts (\%) }\end{array}$ & $\begin{array}{l}\text { No of flat adenomas/ } \\
\text { all benign tumours (\%) }\end{array}$ & $\begin{array}{l}\text { No of flat carcinomas/ } \\
\text { all carcinomas }\end{array}$ \\
\hline Wolber and Owen ${ }^{19}$ & Retrospective & $18 / 210(8.6)$ & $29 / 340(8.5)$ & $2 / 2$ \\
\hline Jaramillo et al ${ }^{k}$ & Prospective & $55 / 178(31.4)$ & $106 / 261$ (40.7) & $3 / 12$ \\
\hline Fujii et $a^{21}$ & Prospective & No data; $47 / 208$ (22) with tumours* & $28 / 68(41)$ & $2 / 7$ \\
\hline Rembacken et a ${ }^{22}$ & Prospective & No data; $225 / 1000$ (22.5) with tumours* & $119 / 321(36.7)$ & $4 / 31$ \\
\hline Lanspa et a ${ }^{20}$ & Prospective & $18 / 148(12)$ & $66 / 136(48.5)$ & None \\
\hline Saitoh et $a{ }^{23}$ & Prospective & $48 / 211(22.7)$ & $57 / 139(44.4)$ & $3 / 57$ \\
\hline Kiesslich et $a^{24}$ & Prospective & No data; $79 / 100$ with tumours* & $5 / 26(19.2)$ & $1 / 6$ \\
\hline
\end{tabular}

*Both protruding and flat tumours. 
1189 patients (pts)

1328 colonoscopies (csp)

\section{Excluded}

Non-high resolution examination 104 pts/121 csp

Non-Europeans FAP/HNPCC IBD $219 \mathrm{pts} / 239 \mathrm{csp}$

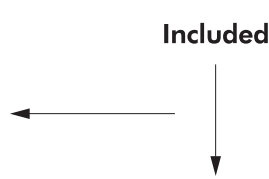

High resolution examination 1085 pts/1207 csp

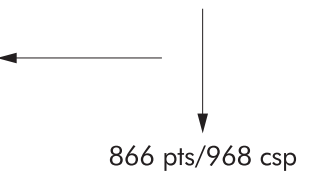

Normal colonoscopy Non-epithelial tumours 494 pts/511 csp

Normal mucosa Non-neoplastic polyps Burned lesion/scanty material 224 lesions

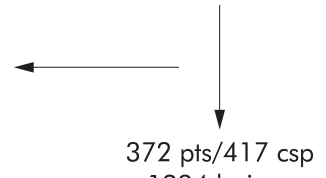

1234 lesions

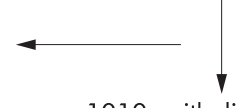

1010 epithelial tumours adenomas (TA, TVA, VA, SA) adenocarcinomas

Inoperable carcinomas 3 pats $/ 3$ tumours

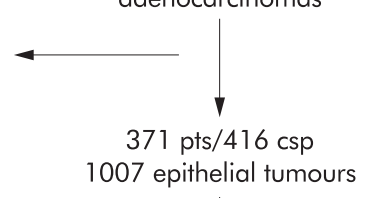

Advanced carcinomas 32 pts/34 tumours

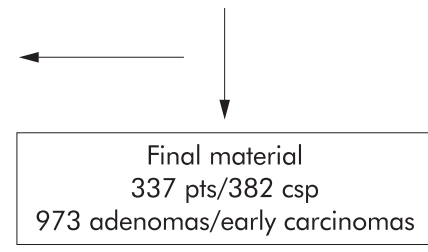

Figure 1 Flow scheme of patients, colonoscopies, and tumours. FAP, familial adenomatous polyposis; HNPCC, hereditary non-polyposis colorectal cancer; IBD, inflammatory bowel disease.

by an experienced Japanese endoscopist at the Endoscopy Unit, Department of Radiology, Malmö University Hospital, Sweden. Included in this study were Europeans who did not suffer from familiar adenomatous polyposis, hereditary non-polypoid colon cancer, or inflammatory bowel disease, and in whom the histological examination revealed an epithelial tumour. Furthermore, all patients in whom the histopathological analysis showed non-neoplastic polyps (hyperplastic, inflammatory, etc) were excluded. Hence the term "tumours" in this paper refers to either adenomas, carcinomas, or both. All patients were informed about the investigations.

All patients were examined by video colonoscopes (Olympus CF 200, Olympus CF 200 Z, Olympus PCF 200). Chromoendoscopy with indigocarmine $(0.1 \%)$ dye spraying was performed in every patient with the slightest hint of a suspicious mucosal change or tiny lesion. In total, 371 patients with 1007 epithelial tumours fulfilled these criteria. The 34 advanced adenocarcinomas found in 34 patients invading the muscularis propria and beyond were excluded from this analysis. Hence 973 tumours in 337 patients formed the study group. The lesions were either biopsied or removed by hot biopsy, strip biopsy, polypectomy, or bowel resection. The 52 patients with flat tumours underwent colonoscopy on 56 occasions, two patients twice and one patient three times.
Specimens were fixed in $4 \%$ buffered formalin overnight and embedded in paraffin. Sections ( $4 \mu \mathrm{m}$ thick) were stained with haematoxylin and eosin. If necessary, serial sections were also prepared. For statistical analysis the $\chi^{2}$ test, the Mann-Whitney U test, and Fisher's exact test were used; a p value less than 0.05 was considered significant.

\section{Endoscopic classification}

The lesions were classified according to the Japanese classification of colorectal carcinoma ${ }^{25}$ with slight modifications. The Japanese system differentiates six different types of carcinomas: type 0 carcinomas are superficial flat lesions with or without minimal elevation or depression; type 1 carcinomas are protruding; type 2 carcinomas are ulcerating with a clear margin; type 3 carcinomas are ulcerating with infiltration; type 4 carcinomas are diffusely infiltrating; and type 5 carcinomas are unclassified. Type 0 is used for carcinomas limited to the submucosa and types 1-5 are used for carcinomas that invade the muscularis propria and beyond. Within the group type 0 , there are two subtypes: type I (protruded) and type II (superficial).

Our classification was as follows: type I tumours were protruding; type II tumours were diagnosed when they were flat or slightly elevated with or without a central depression. Their breadth and length exceeded several times their height. Furthermore, type IIa was slightly elevated, type IIa+IIc was a IIa with central depression, IIc was depressed, and IIc+IIa was a IIc with slight marginal elevation (fig 2A, B). The nodular aggregating lesions were included among type I.

\section{Histopathological classification}

All biopsied and removed lesions were examined under the microscope and reviewed by one pathologist with special interest in gastroenteropathology. Lesions containing dysplastic cells were classified as neoplastic, either adenomas (tubular, tubulovillous, villous, or serrated) or carcinomas. We did not classify aberrant crypt foci as separate entities. The small adenomatous lesions on the surface of the mucosa involving the uppermost part of 1-3 crypts were histologically classified as flat tumours if the mucosa was not elevated endoscopically and were regarded as type I tumours if there was mucosal elevation/protrusion.

There is some confusion in the literature regarding the histopathological terminology of flat and depressed lesions. In recent publications from Japan, type II tumours are called "superficial" adenomas whereas these tumours were designated as "flat adenomas" in the Western literature. We decided to use these two terms synonymously in this paper. The endoscopically identified superficial type II lesions were classified histologically as flat tumours if the height of the tumour was less than twice the thickness of the adjacent normal mucosa (fig 2C). As a rule, these tumours showed radial extension with dysplastic epithelium in the luminal third of the crypts at the periphery of the tumour. Dysplasia was defined as either low or high grade according to the criteria by Riddell. ${ }^{26}$ The category of high grade dysplasia was comprised of "classic" high grade dysplasia, adenocarcinoma in situ, and intramucosal carcinoma (fig 3). Invasive carcinoma was diagnosed when tumour cells were observed within the submucosa or in deeper tissues (fig 4). The presence of dysplastic cells within "crypt inclusions" were not diagnosed as invasion. The term "crypt inclusion" refers to a normal phenomenon when long crypts penetrate the muscularis mucosae and are thus partly situated in the submucosa. Adenocarcinomas with only submucosal invasion were considered as early carcinomas whereas advanced cancers were diagnosed in case of involvement of or beyond the muscularis propria.

\section{RESULTS}

\section{Patients}

Adenomas and early adenocarcinomas were found in 337 patients. Of these, 171 were male and 166 female. Mean ages 

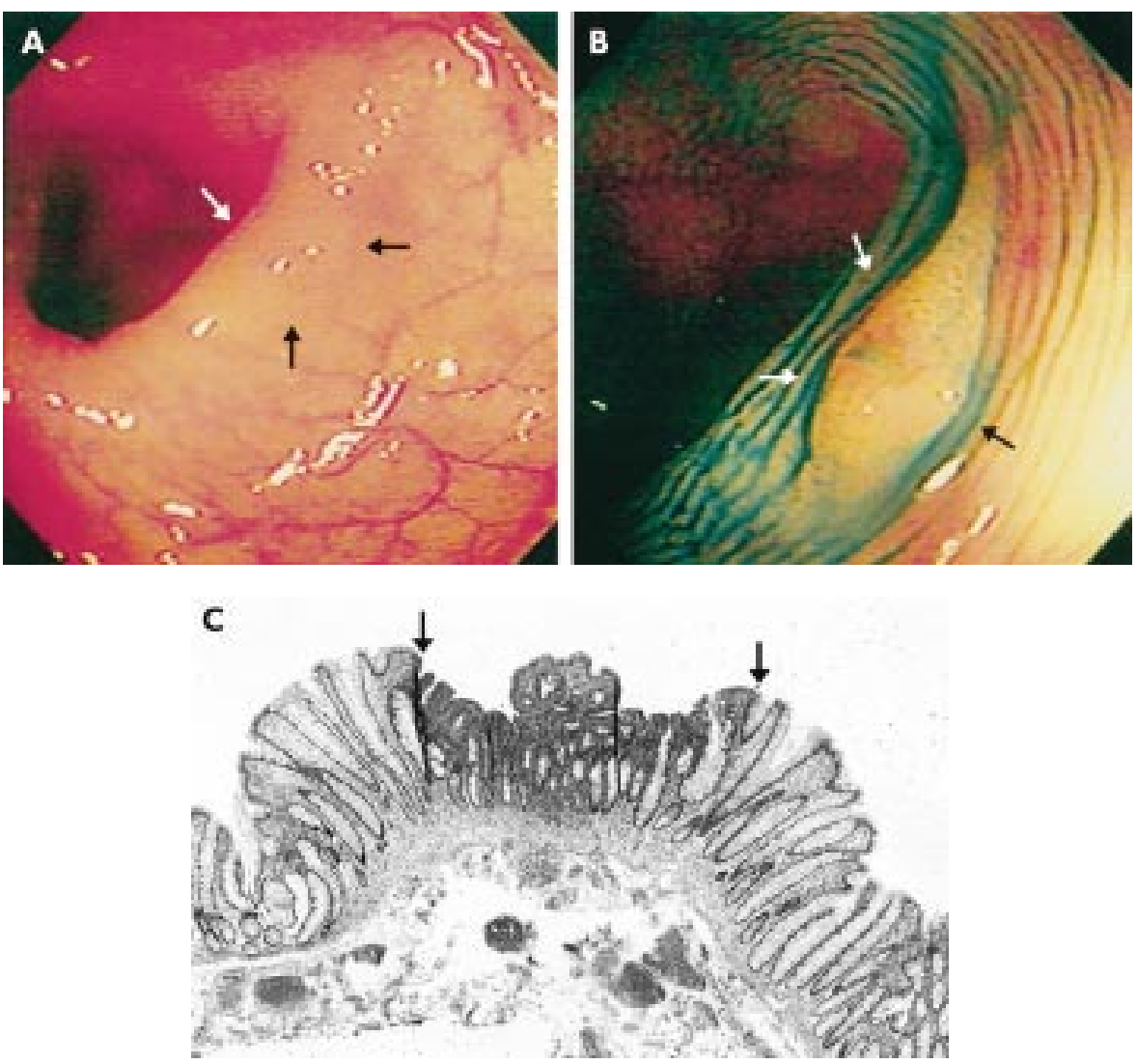

Figure 2 (A) Endoscopic view of a llc+lla lesion, $3 \mathrm{~mm}$ in diameter before dying. The lesion (between the arrows) was discovered by its slight redness. (B) Chromoendoscopic view of the same tumour (between the arrows): following dye spraying the depression was clarified and slight marginal elevation was noted. (C) Low power histological view of the same tumour (between the arrows) showing depression. The central "protrusion" is the result of tangentional sectioning. Haematoxylin and eosin, $\times 40$

were 67 years in males and 68 years in females (range $28-90$ years and 26-87 years, respectively). Indications for colonoscopy are summarised in table 2 .

Superficial type II tumours were found in 52 of 337 patients with adenomas and early carcinomas (15.4\%). Of these, there were 30 females and 22 males (ratio 1.4). Females were somewhat younger than males but the difference was not significant (mean 67 (range 26-84) years and 70 (46-86) years, respectively).

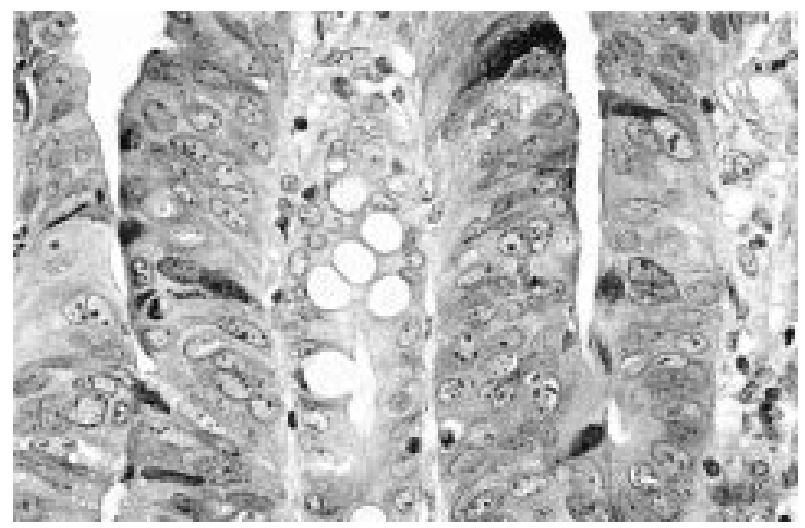

Figure 3 High power view of the superficial part of a flat adenoma. The nuclei are enlarged, vesicular, and rounded containing large nucleoli. There is also clear stratification with at least three layers of nuclei above each other. There is no sign of mucin secretion apart from a few goblet cells. These changes represent high grade dysplasia. No sign of invasion was seen within this tumour. Haematoxylin and eosin, $\times 380$.

\section{Morphology of tumours}

Endoscopically, tumours were diagnosed as either protruding type I lesions (907 tumours, 93.2\%) or superficial type II lesions (66 tumours, $6.8 \%$ ) (table 3 ). The majority of protruding tumours were located in the left colon and rectum $(529 / 907(58.3 \%))$ whereas most flat tumours were found in the right colon (37/66 (56.1\%)). The difference was significant $(\mathrm{p}<0.05)$. Right sided predominance was also found among early flat carcinomas (40\% (2/5) flat cancers $v 27.3 \%(3 / 11)$ protruding tumours). The frequency of carcinoma in protruding type I ( 11/907) and superficial type II (5/66) tumours differed significantly $(\mathrm{p}=0.003)$ (table 3$)$.

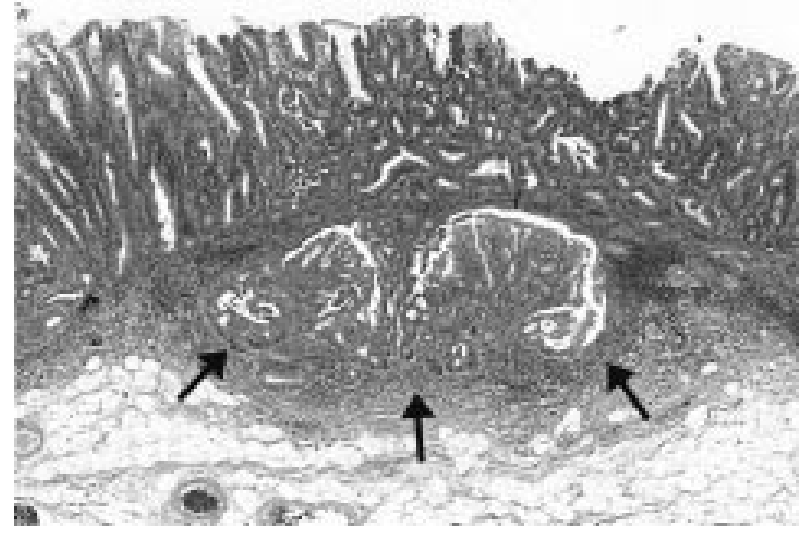

Figure 4 Low power view of a flat carcinoma with invasion of the submucosa (arrows). Haematoxylin and eosin, $\times 40$. 


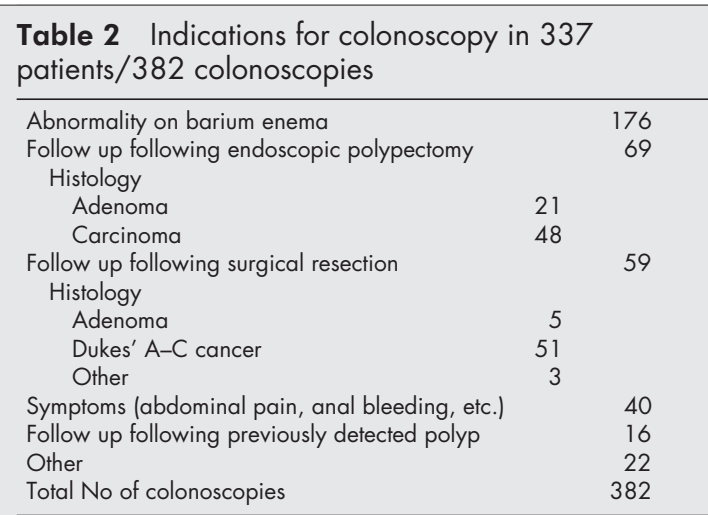

Type II flat adenomas with both low and high grade dysplasia were significantly smaller than their protruding counterparts (table 4). A similar relationship was observed regarding early carcinomas: all flat early carcinomas were less than 20 $\mathrm{mm}$ in diameter with a mean size of $16 \mathrm{~mm}$ (SD 1.3; range 15-18) compared with $28 \mathrm{~mm}(15.8 ; 15-70)$ for protruding neoplasms. Five of the latter were larger than $20 \mathrm{~mm}$ across. Mean endoscopic diameters of type I and type II adenomas with high grade dysplasia were $23 \mathrm{~mm}$ (SD 2.0; range 3-100) and $8 \mathrm{~mm}(5.7 ; 3-20)$, respectively. The difference was highly significant $(\mathrm{p}<0.0001)$ (table 4$)$.

Endoscopically, $77 \%$ of all type II adenomas were of the elevated type IIa $(n=47)$. A central depression (type IIa+IIc) was seen in 12 of these $(20 \%)$ and two tumours were depressed (IIc; IIc+IIa). All but one of the non-elevated tumours were less than $10 \mathrm{~mm}$ in diameter (table 5).

The endoscopic and histological types of the 973 tumours are summarised in table 6 . The majority of the flat lesions were tubular adenomas (58, 87.9\%); five $(7.7 \%)$ were early adenocarcinomas infiltrating the submucosa (fig 4). Villous or serrated tumours were not found among flat lesions. The protruding neoplasms were also dominated by tubular adenomas (73.9\%) but only $1.2 \%$ ( 11 tumours) were early cancers.

\section{Dysplasia in flat and protruding adenomas}

High grade dysplasia (fig 3) was seen in 11 type II adenomas $(18.0 \%)$ and in 65 type I protruding adenomas $(7.3 \%)$ (table $6)$. The difference was highly significant $(p<0.001)$. In nine of $53(16.9 \%)$ type II adenomas of less than $10 \mathrm{~mm}$ in diameter, high grade dysplasia was observed in contrast with type I protruding adenomas of the same size (12/711, 1.7\%) (table 6). The frequency of high grade dysplasia increased with the villous component in protruding adenomas $(2.1 \%, 21.8 \%$, and $42.8 \%$ in tubular, tubulovillous, and villous adenomas, respectively) (table 6).
Table 4 Histological and endoscopic type, grade of dysplasia, number, and endoscopic size of neoplasms

\begin{tabular}{|c|c|c|c|}
\hline & \multirow[b]{2}{*}{ No of tumours } & \multicolumn{2}{|l|}{ Size $(\mathrm{mm})$} \\
\hline & & Mean (SD) & Range \\
\hline \multicolumn{4}{|c|}{ Adenoma LGD } \\
\hline$P$ & 831 & $9(6.5)$ & $2-70$ \\
\hline $\mathrm{F}$ & 50 & $7(4.1)$ & $2-20$ \\
\hline \multicolumn{4}{|c|}{ Adenoma HGD } \\
\hline $\mathrm{P}$ & 65 & $23(2.0)$ & $3-100$ \\
\hline $\mathrm{F}$ & 11 & $8(5.7)$ & $3-20$ \\
\hline \multicolumn{4}{|c|}{ Early (sm) carcinoma } \\
\hline $\mathrm{P}$ & 11 & $28(15.8)$ & $15-70$ \\
\hline $\mathrm{F}$ & 5 & $16(1.3)$ & $15-18$ \\
\hline
\end{tabular}

sm, submucosal invasion; LGD, low grade dysplasia; HGD, high grade dysplasia; $P$, protruding adenoma; $F$, flat/depressed adenoma.

A proportionate relationship was observed between endoscopic type and grade of dysplasia in flat adenomas: in elevated type IIa lesions high grade dysplasia occurred in $12.8 \%(6 / 47)$, and in $35.7 \%(5 / 14)$ in those with a central depression (IIa+IIc or IIc/IIc+IIa) (table 6). In protruding type I adenomas, the grade of dysplasia increased significantly with size, which was not the case in flat neoplasms. Nevertheless, the frequency of high grade dysplasia increased in parallel with size in type IIa adenomas (table 5). There were only three type IIc and IIc+IIa tumours larger than $6 \mathrm{~mm}$ in this material, and hence no relationship between size and grade of dysplasia could be established.

\section{Synchronous neoplastic lesions}

Synchronous flat lesions were found in seven of 52 patients with type II tumours. Four (7.7\%) had two flat tumours, two $(3.8 \%)$ others had three tumours each, and one $(2 \%)$ patient had seven flat tumours. Of these 52 subjects, synchronous protruding tumours were found in every second patient, of whom five had protruding adenocarcinomas.

\section{DISCUSSION}

Indications for colonoscopy in this series showed that all patients were at increased risk of colorectal cancer. They were referred because of a detected or strongly suspected neoplastic lesion on double contrast colonographies, previous polypectomies, colorectal cancer operations, recent rectal bleeding, or change in bowel habit (table 2).

Our observations support previous reports that flat or depressed tumours occur in Western populations. Due to differences in the classification of flat adenomas between Western and Japanese pathologists, comparison of series from Japan and Europe is difficult. ${ }^{15} 27$ Adenomas, which show high

\begin{tabular}{|c|c|c|c|c|c|}
\hline \multirow[b]{2}{*}{ Type } & \multicolumn{2}{|c|}{ Protruding } & \multicolumn{2}{|l|}{ Flat } & \multirow[b]{2}{*}{ Total No (\%) } \\
\hline & Right & Left/rectum & Right & Left/rectum & \\
\hline \multicolumn{6}{|l|}{ Adenoma } \\
\hline LGD & 358 & 473 & 28 & 22 & 881 (90.5) \\
\hline HGD & 17 & 48 & 7 & 4 & 76 (7.9) \\
\hline Early (sm) carcinoma & 3 & 8 & 2 & 3 & $16(1.6)$ \\
\hline Total (sm) & \multicolumn{2}{|c|}{$11^{*}$} & \multicolumn{2}{|c|}{$5^{*}$} & \\
\hline & 378 & 529 & 37 & 29 & $973(100.0)$ \\
\hline Total & \multicolumn{2}{|c|}{907} & \multicolumn{2}{|c|}{66} & \\
\hline
\end{tabular}

*Fisher's exact probability test $=0.003$

sm, submucosal invasion; LGD, low grade dysplasia; HGD, high grade dysplasia. 
Table 5 Endoscopic classification, size, number, high grade dysplasia, and number of carcinomas of flat neoplasms

\begin{tabular}{lrrll}
\hline Type & Size $(\mathrm{mm})$ & Adenoma No & HGD No (\%) & Carcinoma No \\
\hline lla & $1-5$ & 22 & $1(4.5)$ & - \\
& $>5$ to 10 & 18 & $3(16.6)$ & - \\
Ila +llc & $>10$ & 7 & $2(28.6)$ & 1 \\
& $1-5$ & 10 & $4(40.0)$ & - \\
llc (llc+lla) & $>5$ to 10 & 1 & - & - \\
& $>10$ & 1 & - & - \\
Total & $1-5$ & 1 & - & - \\
& $>5$ to 10 & 1 & - & 5 \\
\hline
\end{tabular}

HGD, high grade dysplasia

\begin{tabular}{|c|c|c|c|c|c|}
\hline \multirow{3}{*}{$\begin{array}{l}\text { Histology } \\
\text { Type }\end{array}$} & \multirow[b]{3}{*}{ No } & \multicolumn{4}{|c|}{ Endoscopy } \\
\hline & & \multicolumn{2}{|c|}{ Protruding adenoma } & \multicolumn{2}{|c|}{ Flat/depressed adenoma } \\
\hline & & LGD (n) & $\operatorname{HGD}(n(\%))$ & LGD (n) & HGD (n (\%)) \\
\hline TA & 745 & 671 & $16(2.1)$ & 47 & 11 (18.0) \\
\hline TVA & 179 & 137 & $39(21.8)$ & 3 & - \\
\hline VA & 21 & 12 & $9(42.8)$ & - & - \\
\hline SA & 12 & 11 & $1(7.7)$ & - & - \\
\hline Early (sm) carcinoma & 16 & 11 & & 5 & \\
\hline Total & 973 & 907 & & 66 & \\
\hline
\end{tabular}

grade dysplasia according to Western trained pathologists, are regarded as early carcinomas in Japan and grouped together with cancers invading the submucosa. Furthermore, discrepancy exists even among Japanese pathologists in differentiating high grade dysplasia from early invasive carcinoma. ${ }^{28}$

Flat colorectal tumours were observed in $6.0 \%$ of patients in Malmö (52/866 patients), excluding those with familiar polyposis, hereditary non-polypoid colon cancer, and inflammatory bowel disease. A retrospective study from Canada reported flat adenomas in $8.6 \%$ of 210 patients $^{19}$ whereas flat colorectal tumours occurred in $12.2 \%$ in Omaha. ${ }^{20}$ The other Swedish material from Stockholm cannot be considered in this respect because patients were randomly chosen in that study. ${ }^{6}$ A considerably higher incidence of flat adenomas $(22.7 \%)$ was found in the prospective study performed in Texas, USA. ${ }^{23}$

The incidence of both endoscopically and histologically proved flat epithelial neoplasms among all colorectal epithelial tumours was $6.8 \%$ in the present material, compatible with $8.5 \%$ in the Vancouver report. ${ }^{19}$ These values however are less than those observed in Mainz $\left(19.2 \%{ }^{24}\right)$ and considerably less than those published from Stockholm $\left(42 \%^{6}\right)$, Leeds $\left(41 \%^{21}\right.$ and $36.7 \%^{22}$ ), and Texas $44.4 \%{ }^{23}$ (table 1 ). These latter values are closer to those of the Japanese $(38.7 \% \quad(210 / 542$ non-invasive epithelial tumours $)^{29}$ and $\left.42.9 \%(2498 / 5816)^{30}\right)$. The difference between the two Swedish studies can be explained by the different approaches (randomly chosen versus prospective) whereas the reason for the different values between Leeds and Malmö is unclear. The methods were similar, conducted under the guidance of experienced Japanese endoscopists at both centres.

The female to male ratios in patients with flat adenomas and early carcinomas (1.4) differed significantly from that of protruding tumours $(0.9)$ in our series. In Stockholm there was also a slight female preponderance (1.3). ${ }^{6}$ These observations are in sharp contrast with data from both Canada and
Japan with a male predominance of 1.6 in Vancouver, ${ }^{19} 4.8$ in the original report by Muto and colleagues, ${ }^{7}$ and 3.4 in a second Japanese study. ${ }^{8}$ The Texan study did not analyse the sex distribution of flat tumours. ${ }^{23}$ We have no explanation for the different ratios.

Several series have reported a preponderance of flat adenomas in the right hemi colon: $56 \%$ in our material, $64 \%$ reported by Jaramillo and colleagues, ${ }^{6}$ and $30.9 \%$ by Adachi and colleagues. ${ }^{8}$ In contrast, the Canadian study demonstrated an equal distribution of flat adenomas in the large bowel. ${ }^{19}$ The fact that flat adenomas are more frequent in the right hemi colon is important because it implies that the whole colon should be investigated in the search for these tumours.

Flat adenomas are regarded as having a higher malignant potential than protruding adenomas. The frequency with which high grade dysplasia is found varies however, both in the West and in Japan. In Western countries high grade dysplasia was seen in $14 \%$ in Britain, ${ }^{22}$ in $12 \%$ and $14.7 \%$ in Stockholm, ${ }^{6918}$ in $18.9 \%$ in our series, and in $41 \%$ in Canada. ${ }^{19}$ In Japan, high grade dysplasia has been reported in $8 \%,{ }^{8} 42 \%,{ }^{7}$ and $61 \%$ from the Cancer Institute in Tokyo (including intramucosal carcinoma which is classified as high grade dysplasia in the West) classified by a Western pathologist." A possible explanation for these differences might be selection of patients. Nevertheless, there is agreement between authors that flat tumours with high grade dysplasia or invasive carcinoma are smaller in size compared with protruding tumours. ${ }^{623} 30-32$ These observations are corroborated by the present material.

Colonoscopic observation of a central depression in a flat adenoma is an important warning sign that may predict invasion. Thus Kudo and colleagues ${ }^{30}$ reported that $14.6 \%$ of 130 depressed lesions invaded the submucosa compared with $1.1 \%$ of 2431 non-depressed flat lesions. The corresponding values presented from Sweden were $43 \%$ versus $7 \% .{ }^{6}$ A similar observation was reported from Leeds with only two depressed 
tumours, one of which showed high grade dysplasia and the other was invading the submucosa. ${ }^{21}$ Our observations are in agreement with these data, with high grade dysplasia found in five of 14 IIa+IIc or IIc/IIc+IIa adenomas (35.7\%) versus five of $47(7.1 \%)$ in non-depressed flat adenomas. Furthermore, four of the five flat early adenocarcinomas were IIa+IIc or IIc/ IIc+IIa. Thus it seems justified to support the observation made earlier by others ${ }^{82} 303334$ that a central depression is an ominous endoscopic sign of high risk of malignant transformation. Chromoendoscopy makes it easier to discover the central depression, as was also shown by recent studies. ${ }^{24}{ }^{35} \mathrm{In}$ general, endoscopic discovery of flat and depressed lesions is more reliable after the use of indigocarmine, as was shown in the Texan study: $62 \%$ of lesions were found following dye spraying. ${ }^{23}$

In conclusion, we found flat colorectal neoplasms in a Western population, their incidence being $6.8 \%$ in the present material. They were more often located in the right colon and smaller than their protruding counterparts. High grade dysplasia was revealed both more frequently ( $18.0 \% v 7.3 \%)$ and in smaller (mean $8 \mathrm{~mm} v 23 \mathrm{~mm}$ ) superficial type II than in protruding type I adenomas. Depression should be regarded as an important endoscopic sign predicting an increased risk of invasive carcinoma. Knowledge that flat type II colorectal adenomas occur in Western patients is important and should alert endoscopists to search more vigorously for them so that afflicted patient can be treated and cured. Video colonoscopy combined with dye spraying chromoendoscopy seems to be helpful in this respect.

\section{ACKNOWLEDGEMENTS}

This work was partly supported by Allmänna Sjukhuset i Malmö Stiftelse för Bekämpande av Cancer, Malmö Sjukvårdsförvaltning, Malmö, Sweden. The authors are grateful to Professor Tsuneyoshi Yao and Associate Professor Toshiyuki Matsui, Department of Gastroenterology, Fukuoka University, Chikushi Hospital, Japan for supporting this study. We also thank Olympus Promarketing Co. (Tokyo and Fukuoka, Japan) and Olympus Europe Co. (Hamburg, Germany) for supporting our work.

\section{Authors' affiliations}

S Tsuda, Endoscopy Unit, Department of Radiology, University Hospital Malmö, Sweden, and Department of Gastroenterology, Chikushi Hospital, Fukuoka University, Japan

B Veress, Department of Pathology, University Hospital Malmö, Sweden E Tóth, F-T Fork, Endoscopy Unit, Department of Radiology, University Hospital Malmö, Sweden

\section{REFERENCES}

1 Morson BC. Precancerous and early malignant lesions of the large intestine. Br J Surg 1968;55:725-31.

2 Fenoglio $C M$, Lane $N$. The anatomic precursor of colorectal carcinoma. Cancer 1974;34:819-23.

3 Muto T, Bussey HJR, Morson BC. The evolution of cancer of the colon and rectum. Cancer 1975;36:2251-70.

4 Spratt JS, Ackerman LV. Small primary adenocarcinomas of the colon and rectum. JAMA 1962;179:337-46.

5 Kuramuto S, Oohara T. Minute cancers arising de novo in the hyman large intestine. Cancer 1988;61:829-34.

6 Jaramillo E, Watanabe M, Slezak P, et al. Flat neoplastic lesions of the colon and rectum detected by high-resolution video endoscopy and chromoscopy. Gastrointest Endosc 1995;42:114-22.
7 Muto T, Kamiya J, Sawada T, et al. Small "flat adenoma" of the large bowel with special reference to its clinicopathologic features. Dis Colon Rectum 1985;28:847-51

8 Adachi $M$, Muto T, Okinaga K, et al. Clinicopathologic features of the flat adenoma. Dis Colon Rectum 1991;34:981-6

9 Rubio CA, Kumagai J, Kanamori T, et al. Flat adenomas and flat adenocarcinomas of the colorectal mucosa in Japanese and Swedish patients. A comparative histologic study. Dis Colon Rectum 1995:38: 1075-9

10 Tada S, Yao T, lida M, et al. A clionicopathologic study of small flat colorectal carcinoma. Cancer 1994;74:2430-5.

11 Yao T, Tada S, Tsuneyoshi M. Colorectal counterpart of gastric depressed adenoma. A comparison with flat and polypoid adenomas with special reference to the development of pericryptal fibroblasts. Am Surg Pathol 1994; 18:559-68.

12 Wada R, Matsukuma S, Abe H, et al. Histopathological studies of superficial-type early colorectal carcinoma. Cancer 1996;77:44-50.

13 Colton CG, Sivak MV. Flat adenomas and cancers. Gastrointest Endosc 1995;42:182-4

14 Bond JH. Small flat adenomas appear to have little clinical importance in Western countries. Gastrointest Endosc 1995;42:184-7.

15 Riddell RH, Iwafuchi M. Problems arising from Eastern and Western classification systems for gastrointestinal dysplasia and carcinoma: are they resolvable? Histopathology 1998;33:197-202.

16 Owen DA. Flat adenoma, flat carcinoma, and de novo carcinoma of the colon. Cancer 1996;77:3-6.

17 Kobayashi K, Sivak MV. Flat adenoma: are Western endoscopists careful enough? Endoscopy 1998;30:487-9.

18 Rubio CA, Watanabe T, Masaki T, et al. Histologic differences between flat tubular colorectal neoplasias in Japan and Sweden. In Vivo 1997; 11:93-4.

19 Wolber RA, Owen DA. Flat adenomas of the colon. Hum Pathol $1991 ; 22: 70-4$.

20 Lanspa SJ, Rouse J, Smyrk T, et al. Epidemiologic characteristics of the flat adenoma of Muto. A prospective study. Dis Colon Rectum 992;35:543-6

21 Fujii T, Rembacken BJ, Dixon MF, et al. Flat adenomas in the United Kingdom: are treatable cancers being missed? Endoscopy 1998:30:437-43

22 Rembacken BJ, Fujii T, Cairns A, et al. Flat and depressed colonic neoplasms: a prospective study of 1000 colonoscopies in the UK. Lancet 2000;355:1211-14.

23 Saitoh Y, Waxman I, West B, et al. Prevalence and distinctive biologic features of flat colorectal adenomas in a North American population. Gastroenterology 2001;120:1657-65.

24 Kiesslich R, von Bergh $M$, Hahn $M$, et al. Chromoendoscopy with indigocarmine improves the detection of adenomatous and nonadenomatous lesions in the colon. Endoscopy 2001;33:1001-6.

25 Japanese classification of colorectal carcinoma. Tokyo: YM Kanehara and Co. Ltd, 1997.

26 Riddell RH. Management of colonic dysplasia and adenomas. In: Goldman H, Appelman HD, Kaufman N, eds. Gastrointestinal pathology. Baltimore: Wiliams and Wilkins, 1990:356-75.

27 Riddell RH. East meets West: what is early cancer? Can J Gastroenterol $1999 ; 13: 495-7$

28 Uno Y, Munataka A, Tanaka M. The discrepancy of histologic diagnosis between flat early colon cancers and flat adenomas. Gastrointest Endosc 1994;40: 1-6.

29 Kudo S. Endoscopic mucosal resection of flat and depressed types of early colorectal cancer. Endoscopy 1993;25:455-61.

30 Kudo S, Tamura S, Nakajima T, et al. Depressed type of colorectal cancer. Endoscopy 1995;27:54-7.

31 Watanabe T, Sawada T, Kubota Y, et al. Malignant potential in flat elevations. Dis Colon Rectum 1993:36:548-53.

32 Teixeira CR, Tanaka S, Haruma K, et al. Flat-elevated colorectal neoplasms exhibit a high malignant potential. Oncology 1996;53:89-93.

33 lishi $\mathbf{H}$, Tatsuda $M$, Tsutsui $S$, et al. Early depressed adenocarcinomas of the large intestine. Cancer 1992;69:2406-10.

34 Hisabe T, Tsuda S, Matsui T, et al. Invasive colon cancer derived from a small superficial depressed cancer. Report of a case. Dis Colon Rectum 2000;43(suppl):S98-103.

35 Mitooka H, Fujimori T, Maeda S, et al. Minute flat depressed neoplastic lesions of the colon detected by contrast chromoscopy using an indigo carmine capsule. Gastrointest Endosc 1995;41:453-9. 